\title{
Scholarly Commentary: Prioritising Practice Education through Collaborations
}

The world of work into which new graduate therapists of the $21^{\text {st }}$ century will emerge is a demanding one.... Through exposure to a broad range of fieldwork experiences, the next generation can be better equipped with the vision and the strengths to consolidate and expand the diversity of occupational therapy's territory (Thomas, Penman, \& Williamson, 2005).

\section{Introduction}

The critical importance of practice education in occupational therapy to graduate outcomes and preparedness for practice is well recognised (Doherty, Stagnitti, \& Schoo, 2009; Gray et al., 2012; Holmes et al., 2010) being referred to as the bridge between academic education and occupational therapy practice (Roberts, Hooper, Wood, \& King, 2015). It is also the foundation on which graduates make career choices and develop as professional occupational therapists. Recognition of the importance of practice education is evidenced through a growing international collection of published research into both innovative models and the pedagogy of practice education (Roberts et al., 2015).

Globally, the need to ensure a competent and growing health workforce has led to increasing numbers of health professional education programs which in turn has led to an increasing demand for a more diverse range of placements. No longer confined to the inpatient services of teaching hospitals with one student allocated to one supervisor, practice education has shifted markedly with increasing emphasis on establishing new approaches and models providing students with increased opportunity to experience the diversity of professional roles (Rodger, Thomas, et al., 2008). The need to ensure diversity has resulted in practice education developments such as role emerging placements, collaborative placements, interprofessional placements, participatory community placements as well as new supervisory models, such as two or three or more students being supervised by one practice educator (Rodger et al., 2009; Rodger, Webb, et al., 2008; Thomas et al., 2005). Simultaneously research into occupational therapy practice education has provided a much needed evidence base to support students, practice educators and practice education curricular development.

Professor Sylvia Rodger's contribution to Australian and international literature on practice education spans more than a decade and signifies a passion and commitment to enhancing the quality of practice education through rigorous research into student learning, practice education assessment, models of practice education supervision and practice education quality. However, a review of Professor Rodger's earlier publications suggests a much longer standing interest in practice education. One of her first publications in this area was in the related area of supervisor qualities and the supports required by graduate students undertaking doctoral studies via distance education (Rodger \& Brown, 2000). Perhaps her interest in the processes of supervision provided the spring board into a plethora of research and publications on practice education.

Rodger's involvement with an international group of health professional educators (known as Universities 21) from 2001 onwards, highlighted the need for partnerships between university educators and the professionals that supervise students in practice placement (Rodger, Webb, et al., 2008). The guidelines developed aimed to support practice educators to work collaboratively with health/human service providers to investigate alternative practice education models thus expanding opportunities in the workforce. In response to this international agenda, in 2004 Professor Rodger worked with key stakeholders to instigate the Queensland Occupational Therapy Fieldwork 
Collaborative (QOTFC). Comprising representatives from the three Queensland universities occupational therapy courses, occupational therapy professional bodies, and major publicly funded employers, this initiative produced numerous projects and research studies to enhance practice education in Queensland. The collaboration soon developed into a dynamic forum and collaborative centre for practice education research.

\section{Enhancing practice education through research}

One early outcome of the QOTFC was a project that aimed to engage practicing occupational therapists as hub champions (regional practice education representatives) who were brought together at a Practice Education forum in 2006. Engaging and promoting 'hub champions' as a group of committed and passionate individuals was identified as a mechanism for influencing therapists in their local regions with the aim of enhancing practice education opportunities across the state (Rodger, Thomas, et al., 2008). In leading the consultations with the Queensland Health service, Professor Rodger was critical to the subsequent adoption of the model by Queensland Health whereby 19 part-time practice education/clinical education specialists were employed with the mandate to improve the number and quality of practice education placements with Queensland.

A specific shortage in opportunities to experience mental health practice was identified by QOTFC as a focus and led to a pilot project to develop additional opportunities through innovative models of practice education (Rodger et al., 2009). The project provided promising evidence for the development of alternative models in practice education including role-emerging placement and collaborative models of practice placement supervision. Drawing from Rodger's work, there has been a surge of publications on role-emerging practice education evaluating the models used and exploring the potential benefits and challenges for students (Clarke, Martin, Sadlo, \& de-Visser, 2014; Fieldhouse \& Fedden, 2009; Overton, Clark, \& Thomas, 2009; Thew, Hargreaves, \& CroninDavis, 2008; Thomas \& Rodger, 2011). Ongoing interest in newer models of practice placement is illustrated in the recent systematic review by Professor Rodger and colleagues exploring how students valued role emerging placements to develop their critical thinking and the use of theory to justify practice (Dancza et al., 2013). A support for students and off-site supervisors for role emerging placements, in the form of a theory-informed workbook, has now been developed and evaluated (Dancza, Copley, Rodger, \& Moran, 2016).

\section{Practice Education Evaluation}

The challenge of ensuring accurate and fair evaluation of student performance during practice education has resulted in a range of research by Rodger specifically related to the University of Queensland's Student Placement Evaluation Form (SPEF). The original SPEF ${ }^{\odot}$, developed in 1998 (Allison \& Turpin, 2004; Turpin, Fitzgerald, \& Rodger, 2011), was the first attempt to develop a valid and reliable practice education assessment which complemented Australian entry-level competencies (OT Australia, 1994). The original SPEF ${ }^{\odot}$ and its subsequent revision, the Student Placement Evaluation Form - Revised (SPEF- $R^{\odot}$ ) (Division of Occupational Therapy, 2008) was developed using an action research methodology approach involving practice educators from different programmes and regional areas. This collaborative approach to the development of the assessment ensured its applicability across a wide range of practice education placements and models.

The SPEF- $\mathrm{R}^{\odot}$ (and its predecessor the SPEF ${ }^{\odot}$ ) set a benchmark internationally as one of the most rigorously tested and reliable practice education assessments and has been adopted by all Australian education entry level programmes including bachelors and graduate-entry masters level 
programmes. More recently a series of studies have been undertaken to evaluate the validity and reliability of the revised assessment and confirmed its construct validity and internal consistency (Rodger et al., 2013). A second study investigated the inter-rater and test-retest reliability highlighting the next step in the evaluation of the SPEF- ${ }^{\odot}$ as an assessment (Rodger, Coleman, et al., 2014). The ongoing development of the SPEF- ${ }^{\odot}$ includes an on-line version form with a bank of comments which provides an effective feedback mechanism for students' performance (Rodger, Turpin, et al., 2014). These three studies highlight Professor Rodger's methodical and rigorous approach to the production of an evidence base for practice education. Rodger's work has ensured that practice education pedagogical processes are based on both professional knowledge and evidence based studies.

\section{Quality in Practice Education}

Professor Rodger's contribution to the development of practice education includes an impressive collection of studies related to quality indicators. Quality of practice education has been viewed from the perspective of different stakeholders, including students, practice educators, university academics, consumers and placement organisations

From the perspective of students, the supervisory relationships between the student and practice educator is a critical indicator of practice education quality. Professor Rodger's work has explored students' perspectives of supervisory practices in two studies, both of which demonstrate the critical importance of the supervisory relationships. Students experience quality of practice education when the supervisory relationship is reciprocal and supportive, facilitative of learning and autonomy and provides a 'just right challenge' (Copley, Rodger, Graham, \& Hannay, 2011; Rodger, Thomas, et al., 2014). Similar factors were highlighted by both practice educators and students in a study that considered these perspectives collectively (Rodger, Fitzgerald, et al., 2011). The findings of Rodger and her colleagues were incorporated into the Improving Quality in Practice Placement Guide (IQiPP) (Division of Occupational Therapy, School of Health and Rehabilitation Sciences, 2012).

In comparison, there has been limited research into the benefits of practice education to consumers, supervisors and the organisations that host practice education placements. Together with a range of co-authors, Rodger's works highlights the benefits of practice education beyond just that of educational quality for the student. Though often ignored in the literature, an important quality indicator for practice education is the degree of consumers' satisfaction with student interventions. Rodger, Fitzgerald, et al. (2011) demonstrated that consumers who were seen by students on practice education feel satisfied with the quality of service provided and would recommend the service to family and friends.

For practice educators and practice education settings, quality of practice education also is judged in the degree to which student presence detracts from, or supports the efficiency of the service. Rodger, Stephens, Clark, Ash, and Graves (2011) time use study of occupational therapy students and practice educators in hospital settings suggested that supervisors spend an average of less than 50 minutes per day of placement-related activity. However, the reduction in client contact was compensated for by the students who spent an average of 266 minutes in daily patient care activities, leading to an overall increase in services during the placement period. A subsequent study of time use during practice education also demonstrated increased occasions of service and longer time spent in patient consultations (Rodger et al., 2012). Similarly nutrition and dietetic student and supervisors productivity was not reduced during placement (Ash, Martin, Rodger, Clark, \& Graves, 2015). Further benefits to service organisations have been demonstrated through subsequent recruitment of staff (Rodger et al., 2007). 


\section{Conclusion}

There is no doubt that the current available evidence base for occupational therapy practice education, and by extrapolation for health professional practice education more generally, has been significantly strengthened by the exemplary contribution of Professor Rodger (Hooper \& Rodger, 2016). The scope of the research has been broadened beyond that of reporting practice education experience and educational outcomes to evidencing the development of innovative models, assessment processes and quality improvement factors that will take practice education into the future. This body of work provides a solid foundation for further development and future scientific enquiry and will continue to inform and support the profession in meeting the educational needs of the next generation of professionals. It is true to say that the occupational therapy profession is in considerable debt to Professor Rodger for her leadership in this important area of occupational therapy education. 
References

Allison, H., \& Turpin, M. J. (2004). Development of the student placement evaluation form: A tool for assessing student fieldwork performance. Australian Occupational Therapy Journal, 51(3), 125-132. doi:10.1111/j.1440-1630.2004.00414.x

Ash, S., Martin, E. K., Rodger, S., Clark, M., \& Graves, N. (2015). Student and supervisor productivity change during nutrition and dietetic practice placements: A cohort study. Nutrition \& Dietetics, 72, 163-169. doi:10.1111/1747-0080.12093

Clarke, C., Martin, M., Sadlo, G., \& de-Visser, R. (2014). The development of an authentic professional identity on role-emerging placements. British Journal of Occupational Therapy, 77, 222-229. doi:10.4276/030802214x13990455043368

Copley, J. A., Rodger, S. A., Graham, F. P., \& Hannay, V. A. (2011). Facilitating student occupational therapists' mastery of occupation-centred approaches for working with children. Canadian Journal of Occupational Therapy, 78, 37-44. doi:10.2182/cjot.2011.78.1.5

Dancza, K., Copley, J., Rodger, S., \& Moran, M. (2016). The development of a theory-informed workbook as an additional support for students on role-emerging placements. British Journal of Occupational Therapy, 79(4), 235-243. doi:10.1177/0308022615612806

Dancza, K., Warren, A., Copley, J., Rodger, S., Moran, M., McKay, E., \& Taylor, A. (2013). Learning experiences on role-emerging placements: An exploration from the students' perspective. Australian Occupational Therapy Journal, 60(6), 427-435. doi:10.1111/1440-1630.12079

Division of Occupational Therapy. (2008). User Manual-Revised edition Student Practice Evaluation Form (SPEF)-Revised Edition Package. Brisbane: The University of Queensland.

Division of Occupational Therapy, School of Health and Rehabilitation Sciences. (2012). Improving Quality in Practice Placements - Allied Health (iQIPP-AH): Guides for quality improvement in allied health practice education. Brisbane, Queensland: The University of Queensland.

Doherty, G., Stagnitti, K., \& Schoo, A. M. M. (2009). From student to therapist: Follow up of a first cohort of Bachelor of Occupational Therapy students. Australian Occupational Therapy Journal, 56, 341-349. doi:10.1111/j.1440-1630.2008.00751.x

Fieldhouse, J., \& Fedden, T. (2009). Exploring the learning process on a role-emerging practice placement: A qualitative study. British Journal of Occupational Therapy, 72, 302-307. doi:10.1177/030802260907200705

Gray, M., Clark, M., Penman, M., Smith, J., Bell, J., Thomas, Y., \& Trevan-Hawke, J. (2012). New graduate occupational therapists feelings of preparedness for practice in Australia and Aotearoa/New Zealand. Australian Occupational Therapy Journal, 59, 445-455. doi:10.1111/j.1440-1630.2012.01029.x

Holmes, J. D., Bossers, A. M., Polatajko, H. J., Drynan, D. P., Gallagher, M., O'Sullivan, C. M., .. . Denney, J. L. (2010). 1000 fieldwork hours: Analysis of multi-site evidence. Canadian Journal of Occupational Therapy, 77, 135-143. doi:10.2182/cjot.2010.77.3.2

Hooper, B. R., \& Rodger, S. (2016). She said, she said: A conversation about growing education research in occupational therapy. The Open Journal of Occupational Therapy, 4(3), Article 12. doi:10.15453/2168-6408.1307

Overton, A., Clark, M., \& Thomas, Y. (2009). A review of non-traditional occupational therapy practice placement education: A focus on role-emerging and project placements. British Journal of Occupational Therapy, 72, 294-301. doi:10.1177/030802260907200704

Roberts, M. E., Hooper, B. R., Wood, W. H., \& King, R. M. (2015). An international systematic mapping review of fieldwork education in occupational therapy: Revue de mappage systématique internationale de la formation clinique en ergothérapie. Canadian Journal of Occupational Therapy, 82, 106-118. doi:10.1177/0008417414552187

Rodger, S., \& Brown, G. T. (2000). Enhancing graduate supervision in occupational therapy education through alternative delivery. Occupational Therapy International, 7, 163-172.

doi:10.1002/oti.117 
Rodger, S., Chien, C.-W., Turpin, M., Copley, J., Coleman, A., Brown, T., \& Caine, A.-M. (2013). Establishing the validity and reliability of the Student Practice Evaluation Form-Revised (SPEF-R) in occupational therapy practice education: A rasch analysis. Evaluation and the Health Professions, 39(1), 33-48. doi:10.1177/0163278713511456

Rodger, S., Coleman, A., Caine, A. M., Chien, C.-W., Copley, J., Turpin, M., \& Brown, T. (2014). Examining the inter-rater and test-retest reliability of the Student Practice Evaluation FormRevised (SPEF-R) for occupational therapy students. Australian Occupational Therapy Journal, 61, 353-363. doi:10.1111/1440-1630.12151

Rodger, S., Fitzgerald, C., Davila, W., Millar, F., Springfield, L., Thomas, Y., . . Greber, C. (2011). Consumers' perspectives of quality in student delivered occupational therapy services. Focus on Health Professional Education: A Multidisciplinary Journal, 13(2), 37-52.

Rodger, S., Stephens, E., Clark, M., Ash, S., \& Graves, N. (2011). Occupational therapy students' contribution to occasions of service during practice placements in health settings. Australian Occupational Therapy Journal, 58, 412-418. doi:10.1111/j.1440-1630.2011.00971.x

Rodger, S., Stephens, E., Clark, M., Ash, S., Hurst, C., \& Graves, N. (2012). Productivity and time use during occupational therapy and nutrition/dietetics clinical education: A cohort study. PLOS One, 7(8: e44356). doi:10.1371/journal.pone.0044356

Rodger, S., Thomas, Y., Dickson, D., McBryde, C., Broadbridge, J., Hawkins, R., \& Edwards, A. (2007). Putting students to work: Valuing fieldwork placements as a mechanism for recruitment and shaping the future occupational therapy workforce. Australian Occupational Therapy Journal, 54, S94-S97. doi:10.1111/j.1440-1630.2007.00691.x

Rodger, S., Thomas, Y., Fitzgerald, C., Dickson, D., McBryde, C., Edwards, A., . . Hawkins, R. (2008). Evaluation of a collaborative project to engage occupational therapy clinicians in promoting practice placement education. British Journal of Occupational Therapy, 71, 248-252. doi:10.1177/030802260807100605

Rodger, S., Thomas, Y., Greber, C., Broadbridge, J., Edwards, A., Newton, J., \& Lyons, M. (2014). Attributes of excellence in practice educators: The perspectives of Australian occupational therapy students. Australian Occupational Therapy Journal, 61, 159-167. doi:10.1111/14401630.12096

Rodger, S., Thomas, Y., Holley, S., Springfield, E., Edwards, A., Broadbridge, J., . . Hawkins, R. (2009). Increasing the occupational therapy mental health workforce through innovative practice education: A pilot project. Australian Occupational Therapy Journal, 56, 409-417. doi:10.1111/j.1440-1630.2009.00806.x

Rodger, S., Turpin, M., Copley, J., Coleman, A., Chien, C.-W., Caine, A.-M., \& Brown, T. (2014). Student Practice Evaluation Form-Revised Edition Online comment bank: Development and reliability analysis. Australian Occupational Therapy Journal, 61, 241-248. doi:10.1111/14401630.12115

Rodger, S., Webb, G., Devitt, L., Gilbert, J., Wrightson, P., \& McMeeken, J. (2008). Clinical education and practice placements in the allied health professions: an international perspective. Journal of Allied Health, 37(1), 53-62.

Thew, M., Hargreaves, A., \& Cronin-Davis, J. (2008). An evaluation of a role-emerging practice placement model for a full cohort of occupational therapy students. British Journal of Occupational Therapy, 71, 348-353. doi:10.1177/030802260807100809

Thomas, Y., Penman, M., \& Williamson, P. (2005). Australian and New Zealand fieldwork: Charting the territory for future practice. Australian Occupational Therapy Journal, 52, 78-81. doi:10.1111/j.1440-1630.2004.00452.x

Thomas, Y., \& Rodger, S. (2011). Successful role emerging placements: It is all in the preparation. In M. Thew, M. Edwards, S. Baptiste, \& M. Molineux (Eds.), Role emerging occupational therapy: Maximising occupation focused practice (pp. 39-53). Chichester: Wiley-Blackwell. 
Turpin, M., Fitzgerald, C., \& Rodger, S. (2011). Development of the Student Practice Evaluation Form Revised Edition (SPEF-RC) package. Australian Journal of Occupational Therapy, 58, 67-73. doi:10.1111/j.1440-1630.2010.00890.x 